\title{
Bone marrow mesenchymal stem cells improve myocardial function in a swine model of acute myocardial infarction
}

\author{
JING-JIE ZHAO ${ }^{1}$, XIAO-CHENG LIU ${ }^{2}$, FENG KONG ${ }^{3}$, TONG-GANG QI $^{3}$, \\ GUANG-HUI CHENG ${ }^{3}$, JUE WANG ${ }^{3}$, CHAO SUN $^{3}$ and YUN LUAN ${ }^{3}$ \\ ${ }^{1}$ Clinical Molecular Biology Laboratory, The Second Hospital of Shandong University, Jinan, Shandong 250033; \\ ${ }^{2}$ TEDA International Cardiovascular Hospital and Nankai University Medical College, Tianjin 300457; \\ ${ }^{3}$ Central Research Laboratory, The Second Hospital of Shandong University, Jinan, Shandong 250033, P.R. China
}

Received October 24, 2013; Accepted December 6, 2013

DOI: $10.3892 / \mathrm{mmr} .2014 .2378$

\begin{abstract}
The aim of the current study was to confirm the effect and elucidate the mechanism of bone marrow mesenchymal stem cells (BMSCs) in acute myocardial infarction (AMI). AMI was induced in mini-swine by ligating the left anterior descending coronary artery, and BMSCs $\left(1 \times 10^{7}\right)$ were injected via a sterile microinjection into the ischemic area. Six months postoperatively, electrocardiograph-gated single photon emission computed tomography revealed that the myocardial filling defect was reduced and the left ventricular ejection fraction was improved in the BMSC group compared with the control group $(\mathrm{P}<0.05)$. Histopathological examination indicated that, in the BMSC treatment group, the percentage of survived myocardial tissue and the vessel density were increased, and the percentage of apoptosis was decreased compared with controls $(\mathrm{P}<0.05)$. Reverse transcription-polymerase chain reaction results indicated that the expression levels of multiple inflammatory factors were significantly upregulated in the BMSC group compared with levels in the control group $(\mathrm{P}<0.05)$. In conclusion, the present study demonstrated that BMSC injection significantly improved cardiac function and reduced infarct size in six
\end{abstract}

Correspondence to: Professor Yun Luan, Central Research Laboratory, The Second Hospital of Shandong University, 247 Beiyuan Dajie, Jinan, Shandong 250033, P.R. China

E-mail:y_luan@163.com

Abbreviations: AMI, acute myocardial infarction; BMSCs, bone marrow-derived stem cells; CI, cardiac index; CVP, central venous pressure; $\mathrm{dP} / \mathrm{dt}_{\max }$, velocity of $\mathrm{LV}$ contraction; $\mathrm{dP} / \mathrm{dt}_{\min }$, velocity of LV diastole; EF, ejection fraction; HR, heart rate; LVEDP, left ventricular end-diastolic perfusion; LVEDV, left ventricular end-diastolic volume; LVESV, left ventricular end-systolic volume; MAP, mean arterial pressure; MD, myocardial density; MDP, mass defect percentage; PAWP, pulmonary arterial wedge pressure; $\mathrm{SvO}$, percentage oxygen saturation.

Key words: AMI, BMSCs, transplantation months, indicating that this method may be valuable for future study in clinical trials.

\section{Introduction}

According to 2011 statistics, acute myocardial infarction (AMI) is one of the most prevalent causes of death and morbidity $(1,2)$. Adult cardiomyocytes lack the capacity for regeneration, so scar tissue replaces lost myocardium following myocardial infarction, and this leads to cardiac remodeling with reduced left ventricular (LV) function (3). Cell therapy is a potential method for the regeneration and repair of myocardium and the improvement of myocardial function following ischemic injury (4). A number of cell types, including foetal Flk1 ${ }^{+} \mathrm{CD} 34^{+} \mathrm{CD} 31^{-}$bone marrow stem cells (BMSCs) have demonstrated cardiac regenerative capacity (5), however, the mechanism that stem cell transplantation utilizes in order to improve cardiac function following ischemic heart disease is unclear and there is little information available regarding the medium- and long-term effects. On the other hand, there exist a variety of transplantation methods, including local intramyocardial injection, intravenous injection, and intracoronary injection to the infarct zone (6). Intramyocardial injection of BMSCs has been demonstrated to be safe, and to lead to reverse remodeling and improved contractile ability of scarred areas $(3,7)$. The mechanisms by which BMSCs reduce infarct size and improve cardiac function in animal models are complicated, involving engraftment, differentiation into functional cardiomyocytes and paracrine signaling $(8,9)$. In the present study, fetal $\mathrm{Flk} 1^{+} \mathrm{CD} 34^{+} \mathrm{CD} 31^{-} \mathrm{BMSC}$ were transplanted via intramyocardial injection of the mini-swine, then the myocardial function, stem cell migration and extent of survival in the myocardium was evaluated. The current study was therefore designed to determine the long-term (6-month) effect and mechanism of BMSCs in AMI.

\section{Materials and methods}

Animals. Mini-swine weighing $25-30 \mathrm{~kg}$ were purchased from The Experimental Animal Breeding Center of Beijing, China. All animals received humane care in compliance with the Guide for the Care and Use of Laboratory Animals published 
by the U.S. National Institute of Health (NIH Publication no. 85-23, 1996). The present study was approved by the Ethics Committee of Shandong University (Jinan, China).

Isolation, culture and immunophenotype analysis of BMSCs. BMSCs were isolated, cultured and immunophenotyped using the methods of previous studies $(10,11)$. Under general anesthesia maintained by intramuscular injection of ketamine $\left(10 \mathrm{mg} \cdot \mathrm{kg}^{-1}\right)$ followed by an intravenous drip of sodium pentobarbital $\left(30 \mathrm{mg} \cdot \mathrm{kg}^{-1}\right)$, bone marrow $(20 \mathrm{ml})$ was aspirated from the anterior iliac crest with a syringe (Beijing Nianyou Medical Instrument Co., Ltd., Beijing, China) containing 6,000 $\mathrm{U}$ heparin with a myeloid puncture needle. To separate BMSCs from other cells, the Ficoll $\left(1.077 \mathrm{~g} \cdot \mathrm{ml}^{-1}\right)$ density gradient centrifugation method was used. Following centrifugation at $1,000 \mathrm{~g}$ for $10 \mathrm{~min}$ at $20^{\circ} \mathrm{C}$, the white layer composed of mononuclear cells from the upper section and interface was carefully collected and washed three times with phosphate-buffered saline (PBS) prior to final resuspension in $10 \mathrm{ml}$ heparinized saline. The cell pellet was then resuspended in Dulbecco's modified Eagle's medium/F12 (1:1). When adherent cells were confluent (defined as passage 0 ), they were continuously cultured until passage 3-5 in trypsin $(0.25 \%)$ and $1 \mathrm{mmol} / 1$ ethylenediamine-tetraacetic acid (Sigma-Aldrich, St. Louis, MO, USA) for 5 mins. All cultures were maintained at $37^{\circ} \mathrm{C}$ in a $95 \%$ humidified incubator at $37^{\circ} \mathrm{C}$ and $5 \% \mathrm{CO}_{2}$, and the cultures were replenished with fresh medium every 3 days. For immunophenotyping, cells were washed twice with PBS containing $0.5 \%$ bovine serum albumin (Sigma-Aldrich) and then suspended in PBS and incubated with primary antibodies raised against human CD34; Flk1 (Santa Cruz Biotechnology, Santa Cruz, CA, USA); CD44; CD31; CD29; CD105; CD106; and HLA-ABC (BD Pharmingen, San Diego, CA, USA) for $30 \mathrm{~min}$ at $4^{\circ} \mathrm{C}$. The secondary polyclonal antibody (ZSGB-Bio Co., Beijing, China) was added and incubated at $4^{\circ} \mathrm{C}$ for an additional $30 \mathrm{~min}$ in a dark room. An isotype control antibody from the same species was used as a negative control. Following washing, cells were resuspended in PBS for fluorescence activated cell sorting (FACS) analysis.

Acute myocardial infarction model and stem cell transplantation. A mini-swine model of AMI was generated by ligating the left anterior descending artery (LAD) using the method of a previous study (10): Under general anesthesia, animals were intubated and positive pressure ventilation was maintained. The middle third of the LAD was ligated following three intermittent brief preconditioning occlusions, each for $5 \mathrm{~min}$. A bolus of lignocaine was given intravenously $\left(1 \mathrm{mg} \mathrm{kg}^{-1}\right)$ and then maintained at $1 \mathrm{mg} \mathrm{min}{ }^{-1} \mathrm{~kg}^{-1}$ with an intravenous drip. Subsequently, the eligible animals were randomly divided into non-treatment (control) and BMSC treatment groups (10 in each group). Following coronary ligation, cells $\left(1 \times 10^{7}\right)$ in $100 \mu \mathrm{l}$ saline were injected into animals of the BMSC group with a sterile microinjection at 5 ischemic sites. The needle was advanced $5 \mathrm{~mm}$ into the myocardium and the cells were injected at $1.5 \mathrm{~mm}$. Hemostasis was performed and the chest was closed in layers. Postoperatively, penicillin G benzathine (30,000 U/day; Qilu Pharmaceutical Co., Ltd., Jinan, China) was administered intravenously for 3 days.
Left ventricular function analysis. Via right external jugular access, a 7F Swan-Ganz catheter (Edwards Lifesciences, Irvine, CA, USA) was advanced into the pulmonary artery for the assessment of cardiac output, pulmonary arterial wedge pressure and central venous pressure using the MP150 system (Biopac Systems, Inc., Goleta, CA, USA) with output to computer at a sampling rate of $1 \mathrm{kHz}$, using Biopac AcqKnowledge software at the following time points: Pre-ligation, 30 min post-ligation, and 6 months post-treatment. Two pressure catheters were placed in the aorta and LV to monitor pressure. The maximum velocity of LV contraction $\left(\mathrm{dP} / \mathrm{dt}_{\max }\right)$ and the maximum velocity of $\mathrm{LV}$ diastole $\left(\mathrm{dP} / \mathrm{dt}_{\min }\right)$ were used to assess LV function.

Myocardial perfusion analysis. Following intravenous administration of nitroglycerin $(0.4 \mathrm{mg})(12)$, all animals received $14.8 \mathrm{MB} \mathrm{q} \mathrm{kg}^{-1} 99 \mathrm{mTc}$-sestamibi (Institute of Atomic Energy, Beijing, China) at $6^{\circ}$ per frame. A total of $180^{\circ}$ was received by rotating a $64 \times 64$ matrix detector in a $20 \%$ energy window using electrocardiograph-gated single photon emission computed tomography (SPECT; Millennium vG-5; GE Healthcare, CT, USA), with reconstruction parameters as follows: Prefilter, Butterworth filter; critical frequency, 0.52; and power, 5.0. Analysis of changes in mass defect percentage (MDP), and determination of end diastolic volume (EDV), end systolic volume (ESV) and ejection fraction (EF) were performed using Emory Cardiac Toolbox software (ECTb; GE Healthcare).

Immunological and immunohistochemical analysis. The animals were sacrificed by intracoronary perfusion of $10 \%$ $\mathrm{KCl}$ solution 3 months postoperatively. The hearts were quickly harvested and the tissues in the infarcted zone were collected and fixed with $10 \%$ formaldehyde (Shanghai Sunshine Reagent Co., Ltd., Shanghai, China). Serial sections $(5-\mu \mathrm{m})$ were stained with Masson's stain (Baso Biotechnology, Shenzhen, China) to detect the myofilament structure, and sections were captured as digital images. Myocardial density (MD) was quantified with the Image Pro Plus software package, version 6.0 (IPP, Media Cybernetics, Rockville, MD, USA). To evaluate the effect of combined therapy on angiogenesis, sections of each group were stained with rabbit anti-human von Willebrand factor (vWF) antibody (DakoCytomation, CPH, Denmark). The vascular density was measured with the IPP software in five non-overlapping fields (magnification, x100). Positively stained areas were padded with a single color and converted to pixels through optical density (OD) calibration.

Terminal deoxynucleotidyl transferase dUTP nick end labeling (TUNEL) assay. The TUNEL method was used to detect levels of cell apoptosis in the infarction zone according to the In Situ Cell Death Detection kit (Roche Diagnostics, Mannheim, Germany). Briefly, deparaffinized 5- $\mu \mathrm{m}$ sections were incubated at $37^{\circ} \mathrm{C}$ for $1 \mathrm{~h}$ with $50 \mu \mathrm{l}$ TUNEL reaction mixture [5 $\mu 1$ terminal desoxynucleotidyl-transferase (TdT) and $45 \mu \mathrm{l}$ dUTP-biotin] following proteinase $\mathrm{K}$ treatment. In the negative control, TdT was omitted, and positive controls were pretreated with DNAse A. Sections were visualized and photographed with a BX41 Microscope (Olympus America Inc., Center Valley, PA, USA) equipped with a digital camera. 
Table I. Hemodynamic parameters of left ventricular function pre- and post-ligation.

\begin{tabular}{|c|c|c|c|}
\hline Parameter & Pre-ligation & Post-ligation & P-value \\
\hline HR (beats/min) & $73.00 \pm 5.00$ & $72.00 \pm 3.00$ & 1.000 \\
\hline CVP (mmHg) & $3.45 \pm 0.62$ & $3.53 \pm 0.58$ & 1.000 \\
\hline MAP (mmHg) & $93.57 \pm 3.65$ & $93.83 \pm 347$ & 0.506 \\
\hline PAWP (mmHg) & $6.48 \pm 0.76$ & $6.51 \pm 0.69$ & 0.804 \\
\hline LVEDP (mmHg) & $6.39 \pm 0.78$ & $6.72 \pm 0.85^{\mathrm{a}}$ & 0.033 \\
\hline $\mathrm{CI}\left(1 / \mathrm{min} / \mathrm{m}^{2}\right)$ & $5.38 \pm 0.13$ & $5.06 \pm 0.18^{\mathrm{a}}$ & $<0.001$ \\
\hline $\mathrm{dP} / \mathrm{dt}_{\max }(\mathrm{mmHg} / \mathrm{sec})$ & $3489 \pm 189$ & $2988 \pm 186^{\mathrm{a}}$ & $<0.001$ \\
\hline $\mathrm{dP} / \mathrm{dt}_{\min }(\mathrm{mmHg} / \mathrm{sec})$ & $-1908 \pm 96$ & $-1475 \pm 97^{a}$ & $<0.001$ \\
\hline $\mathrm{SvO}_{2}(\%)$ & $78.49 \pm 4.28$ & $76.28 \pm 2.37$ & 0.509 \\
\hline LVEDV (ml) & $115.0 \pm 16.0$ & $129 \pm 19^{a}$ & $<0.001$ \\
\hline LVESV (ml) & $29.0 \pm 2.3$ & $45.0 \pm 3.6^{\mathrm{a}}$ & $<0.001$ \\
\hline $\mathrm{EF}(\%)$ & $68.2 \pm 8.0$ & $50.3 \pm 6.0^{\mathrm{a}}$ & $<0.001$ \\
\hline
\end{tabular}

${ }^{a} \mathrm{P}<0.05$ vs . pre-ligation. HR, heart rate; CVP, central venous pressure; MAP, mean arterial pressure; PAWP, pulmonary arterial wedge pressure; LVEDP, left ventricular end-diastolic perfusion; CI, cardiac index; $\mathrm{SvO}_{2}$, percentage oxygen saturation; LVEDV, left ventricular end-diastolic volume; LVESV, left ventricular end-systolic volume; EF, ejection fraction.

Table II. Hemodynamic parameters of left ventricular function 6 months following surgery.

\begin{tabular}{lcc}
\hline Parameter & Control & BMSCs \\
\hline $\mathrm{HR}($ beats/min) & $73 \pm 4$ & $73 \pm 2$ \\
$\mathrm{CVP}(\mathrm{mmHg})$ & $3.96 \pm 0.41$ & $4.02 \pm 0.39$ \\
$\mathrm{MAP}(\mathrm{mmHg})$ & $94.8 \pm 5.1$ & $94.3 \pm 6.8$ \\
$\mathrm{PAWP}(\mathrm{mmHg})$ & $7.33 \pm 1.03$ & $7.07 \pm 0.77$ \\
$\mathrm{LVEDP}(\mathrm{mmHg})$ & $9.24 \pm 0.18$ & $7.4 \pm 0.15^{\mathrm{a}}$ \\
$\mathrm{dP}_{\mathrm{dt}}(\mathrm{mmHg} / \mathrm{sec})$ & $1710 \pm 112$ & $2530 \pm 174^{\mathrm{a}}$ \\
$\mathrm{dP} / \mathrm{dt}_{\min }(\mathrm{mmHg} / \mathrm{sec})$ & $-648 \pm 27$ & $-1045 \pm 89^{\mathrm{a}}$ \\
$\mathrm{LVEDV}(\mathrm{ml})$ & $162.5 \pm 14.5$ & $135.3 \pm 13.9^{\mathrm{a}}$ \\
$\mathrm{LVESV}(\mathrm{ml})$ & $83.2 \pm 6.3$ & $61.2 \pm 5.1^{\mathrm{a}}$ \\
$\mathrm{EF}(\%)$ & $50.6 \pm 5.3$ & $62.7 \pm 6.2^{\mathrm{a}}$ \\
$\mathrm{CI}\left(\mathrm{l} / \mathrm{min} / \mathrm{m}^{2}\right)$ & $4.80 \pm 0.28$ & $4.82 \pm 0.38$ \\
$\mathrm{SvO}(\%)$ & $74.5 \pm 3.4$ & $76.7 \pm 2.8$ \\
$\mathrm{Hb}(\mathrm{g} / \mathrm{dl})$ & $9.28 \pm 0.32$ & $9.22 \pm 0.29$ \\
\hline
\end{tabular}

${ }^{a} \mathrm{P}<0.05$ vs. control group. BMSCs, bone marrow-derived stem cells. SHR, heart rate; CVP, central venous pressure; MAP, mean arterial pressure; PAWP, pulmonary arterial wedge pressure; LVEDP, left ventricular end-diastolic perfusion; CI, cardiac index; $\mathrm{SvO}_{2}$, percentage oxygen saturation; LVEDV, left ventricular end-diastolic volume; LVESV, left ventricular end-systolic volume; EF, ejection fraction.

TUNEL-positive cells were observed under a microscope (magnification, x200).

Reverse transcription polymerase chain reaction (RT-PCR). Once the hearts were collected and total RNA was extracted from cardiac tissue with TRIzol (Invitrogen, Life Technologies, Carlsbad, CA, USA). RT-PCR analysis was performed to detect the relative pulmonary expression levels of vascular endothelial growth factor (VEGF), vWF, transforming growth factor- $\beta 3$ (TGF- $\beta 3$ ) and interleukin-1 $\beta$ (IL-1 $\beta$ ) as previously described (10). Glyceraldehyde-3-phosphate dehydrogenase was used as an internal control for RNA input level. The sequences of primers and reaction conditions are described in our previous study (10). Following RT-PCR, 1\% agarose gel electrophoresis was performed and the UVI pro gel documentation system (Uvitec, Cambridge, UK) was used for semi-quantification analysis of each PCR product.

Statistical analysis. Statistical analysis was conducted using SPSS, version 13.0 (SPSS, Inc. Chicago, IL, USA). The paired student's t-test was used for self-comparison. The independent samples student's t-test was used to compare experimental measurements between two groups. Data are presented as the mean \pm standard deviation, and $\mathrm{P}<0.05$ was considered to indicate a statistically significant difference.

\section{Results}

Characterization of cultured BMSCs. Following primary culture for 4 days, the mini-swine BMSCs appeared as colonies of large flat cells or spindle-like cells, and the cells were attached to the culture dish tightly and proliferated rapidly in the culture medium (10). FACS analysis indicated that the cells did not express the endothelial marker CD31. The proportion of Flk1 $1^{+}$cells was about $60 \%(11,12)$. After $48 \mathrm{~h}$, the transfection rates reached $80 \%$.

Left ventricular and myocardial perfusion function. Following the ligation of the LAD, the left ventricular EF was significantly reduced, while the EDV and ESV were significantly increased, compared with pre-ligation $(\mathrm{P}<0.05$; Table I). No significant differences were identified in the baseline data of the two groups. This indicates the successful establishment of an AMI model (Table I). Six months after the operation, the hemodynamic parameters, including EF, EDV and ESV in the 
A
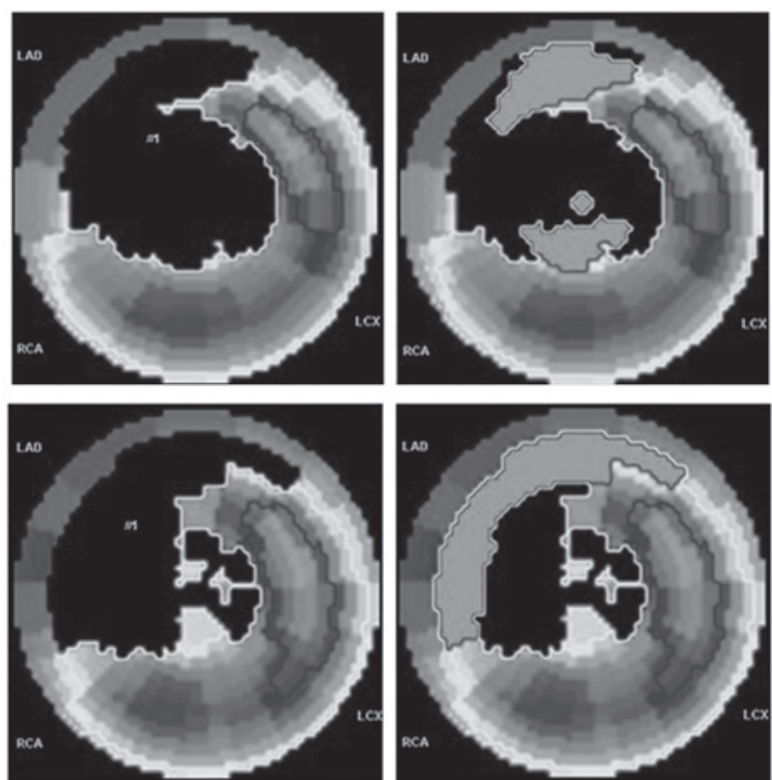

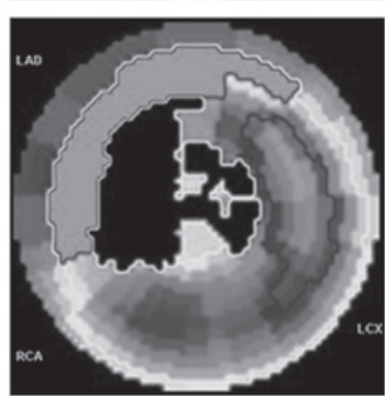

B

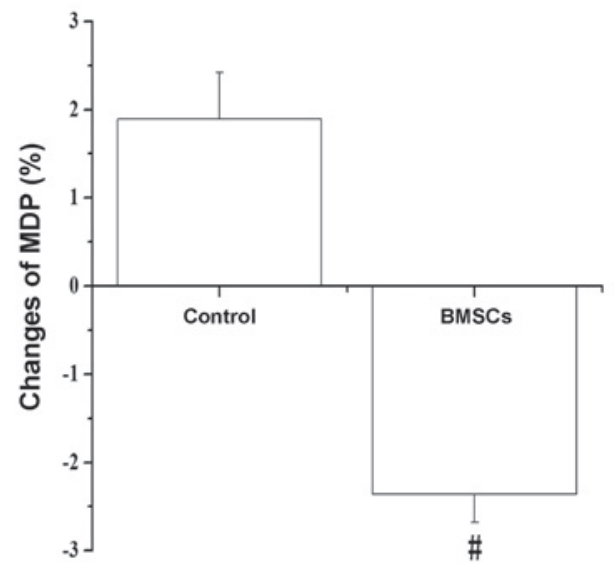

Figure 1.99mTc-SPECT imaging. (A) Upper panel: Control. Lower panel: BMSC-injected. The perfusion defect was visibly enlarged in the control group, but significantly reduced in the BMSC group. (B) MDP was significantly reduced in the BMSC group ( ${ }^{A} \mathrm{P}<0.05$ vs. control group). MDP, mass defect percentage; BMSCs, bone marrow-derived stem cells; SPECT, single photon emission computed tomography.
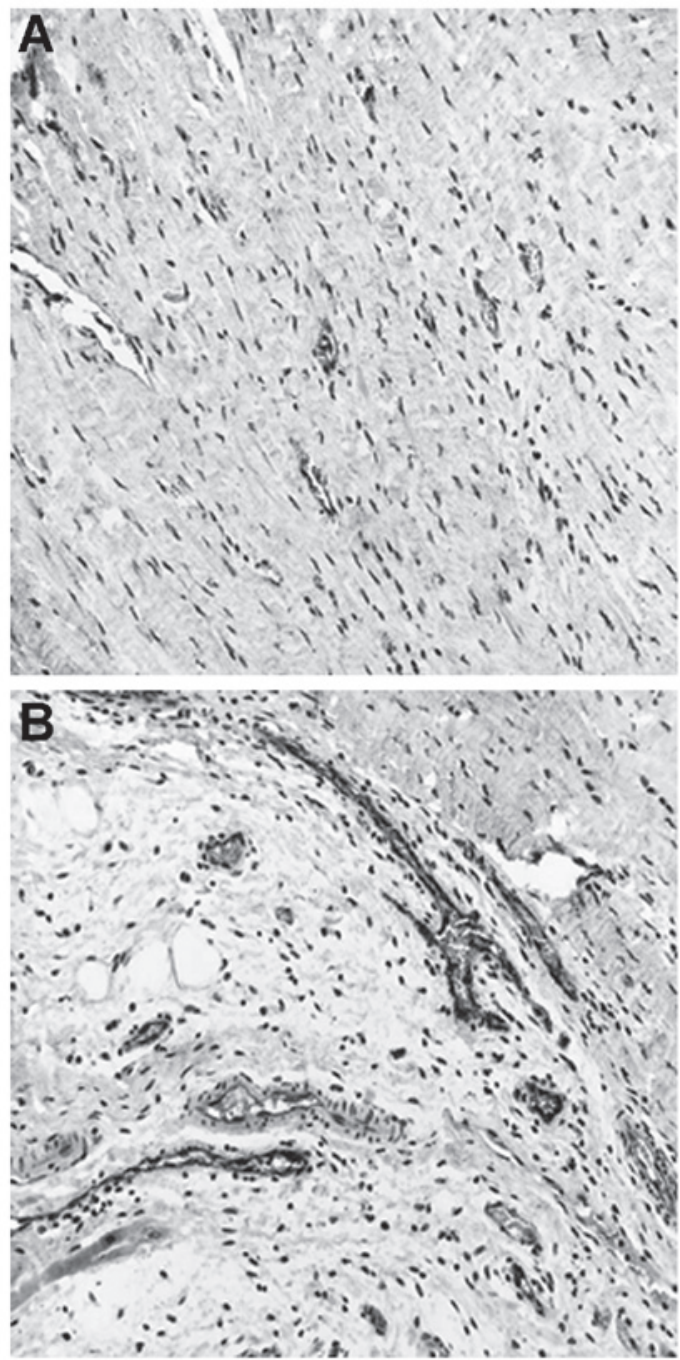

Figure 2. Vessel density analysis with vWF-staining. (A) Control; (B) BMSC-injected (magnification, x100). vWF, von Willebrand factor; BMSC, bone marrow-derived stem cells.
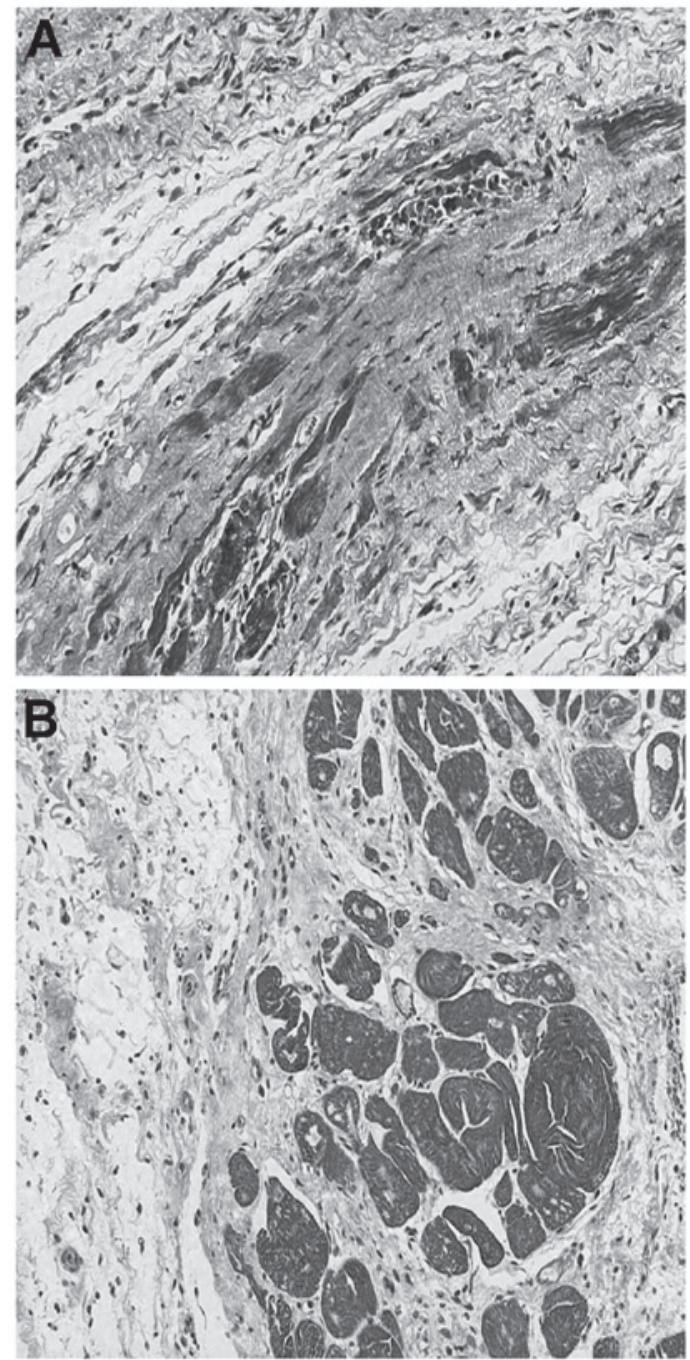

Figure 3. Survived myocardial tissue analysis with Masson's trichrome staining. (A) Control; (B) BMSC-infected (magnification, x100). BMSCs, bone marrow-derived stem cells. 


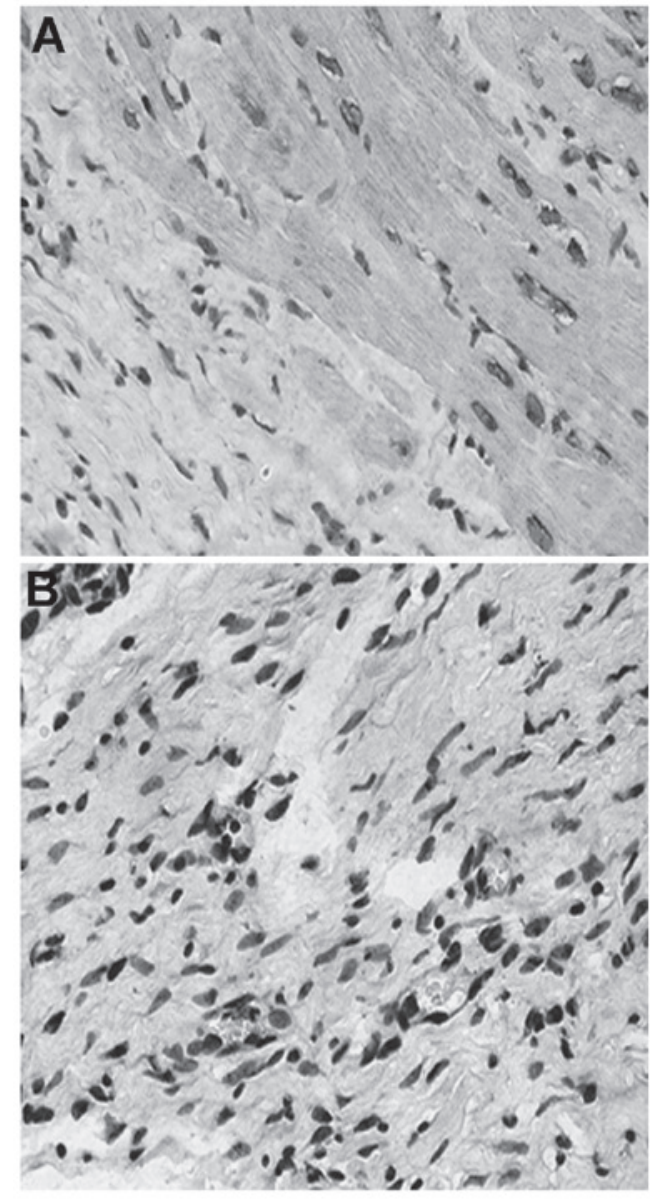

C

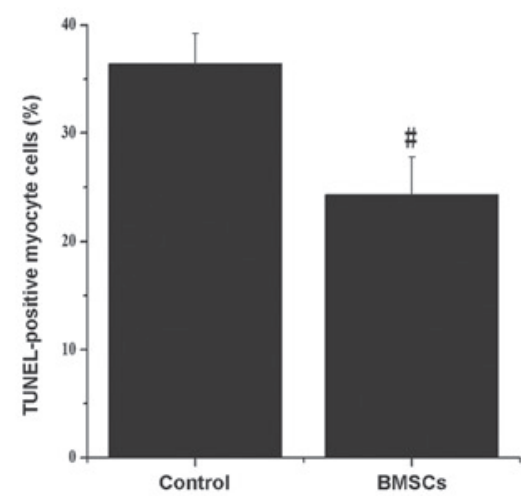

Figure 4. Apoptosis measurement by TUNEL. (A) Control; (B) BMSC-injected; (C) the number of TUNEL-positive cells (brown nuclei) was significantly reduced in the BMSC group (magnification, $\mathrm{x} 400$ ). ${ }^{*} \mathrm{P}<0.05$ vs. control group. TUNEL, terminal deoxynucleotidyl transferase dUTP nick end labeling; BMSC, bone marrow-derived stem cells.

BMSC group displayed a significant improvement compared with the control group $(\mathrm{P}<0.01$; Table II).

Myocardial perfusion was reflected by $99 m T$-SPECT myocardial imaging. The image results revealed that the perfusion defect was visibly enlarged in the control group, but significantly reduced in the BMSC group (Fig. 1A); MDP underwent a significant reduction in the BMSC group $(-2.36 \pm 0.32)$ compared with the level in the control group $(1.89 \pm 0.53)(\mathrm{P}<0.05$; Fig. 1B). This indicates that the mass
A
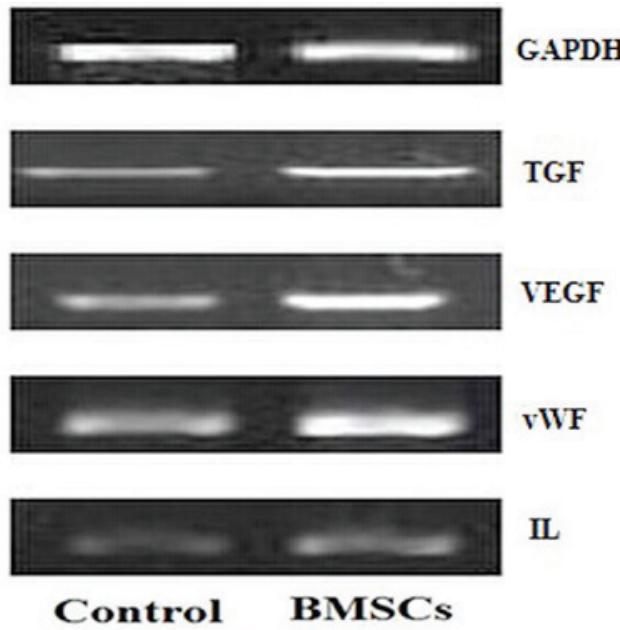

IL

B

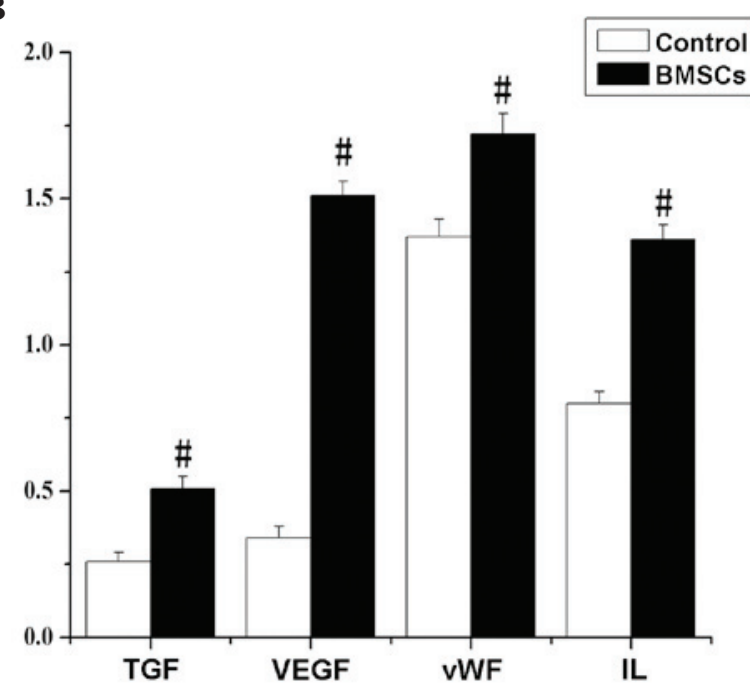

Figure 5. Reverse transcription polymerase chain reaction analysis (A) Gels exhibiting VEGF, vWF, TGF- $\beta$ and IL- $1 \beta$ mRNA expression. (B) mRNA expression levels. ${ }^{\prime} \mathrm{P}<0.05$ vs. the control group. BMSCs, bone marrow-derived stem cells; TGF, transforming growth factor; VEGF, vascular endothelial growth factor; vWF, von Willebrand factor; IL, interleukin.

of infarct-related defect myocardium was reduced and the regional myocardial blood flow was increased.

Vessel and myocardial density analysis. The vessel density was determined by histological staining (vWF) of the infarcted area (Fig. 2). A significant increase in the BMSC group OD $(\mathrm{OD}=5,327+401 \mathrm{pixels} / \mathrm{hpf})$ was observed, compared with that of the control group $(\mathrm{OD}=2,511+308$ pixels/hpf $)(\mathrm{P}<0.05)$.

Masson's trichrome staining. Survived myocardial tissue in the infarcted area was significantly greater in the BMSC group compared with that of the control group (Fig. 3). Following calculations, MD demonstrated significant increases in myocardial viability in the BMSC group $(\mathrm{OD}=80,402 \pm 3,015$ pixels $/ \mathrm{hpf})$ compared with that in control group $(\mathrm{OD}=25,340 \pm 2,918$ pixels/hpf, $\mathrm{P}<0.05)$.

Apoptosis measurement. Myocardial apoptosis was detected by TUNEL staining (Fig. 4A and B). Following calculations, 
the number of TUNEL-positive myocytes was significantly reduced in the BMSC group (24.3 \pm 3.5$)$ compared with levels in the control group (36.4 \pm 2.8$)$ (Fig. 4C; $\mathrm{P}<0.05)$.

RT-PCR analysis. RT-PCR results demonstrated that the expression levels of VEGF, vWF, TGF-3 $\beta$ and IL-1 $\beta$ in the infarction zone were significantly increased in the BMSC group compared with levels in the control group $(\mathrm{P}<0.05$; Fig. 5).

\section{Discussion}

In the current study, $\mathrm{Flk} 1^{+} \mathrm{CD} 34^{+} \mathrm{CD} 3^{-} \mathrm{BMSCs}$ were intramyocardially injected into a mini-swine model of AMI. Six months later, the results indicated that: i) Myocardial filling defect was reduced and left ventricular ejection fraction was increased; ii) the percentage of apoptosis was decreased and the survived myocardial tissue was increased; iii) vessel density was augmented and a number of inflammatory cytokines were upregulated; and iv) the transplantation cells were able to survive in vivo and were concentrated around blood vessels. To the best of our knowledge, the present study demonstrated for the first time, the mid-term effect of BMSCs in an AMI animal model, and revealed a possible mechanism.

BMSCs are multipotent progenitor cells derived from the fetal bone marrow, and have the characteristics of self-renewal and multiple differentiation potential. Following direct injection into an infarcted heart, the cells have been demonstrated to improve cardiac function $(13,14)$, decrease fibrous tissue accumulation (15), and repair cardiac infarcts (16). BMSCs are easy to obtain and have a high transfection efficiency, and therefore are ideal for genetic engineering and clinical applications (17). Although BMSC transplantation has provided a promising therapeutic option, the protective effect in clinical trials remains controversial (18). In fact, many questions remain unsolved (19), including the choice of animal for the model, and the transplantation method. On the other hand, most studies have focused on the short-term effects of BMSC transplantation (14-20), and studies on medium and long-term effects are few (21). Intramyocardial injection of MSCs has been demonstrated to be safe in large animal models $(5,11)$, and in the present study, 6 months following intramyocardial injection of $\mathrm{Flk} 1^{+} \mathrm{CD} 34^{+} \mathrm{CD} 3-\mathrm{BMSCs}$, SPECT detection indicated that the myocardial filling defect was reduced and LV ejection fraction was significantly improved in AMI models injected with BMSCs compared with uninjected models. Histopathological examination indicated that the area covered by the myocardial infarction and the percentage of cells undergoing apoptosis were reduced; and the percentage of survived myocardial tissue and the vessel densities were augmented, following BMSC injection ( $\mathrm{P}<0.05$, compared with controls).

As reported previously, the effect of paracrine signaling may further improve angiogenesis (20,22-26). It has been demonstrated that BMSCs secrete angiogenic and anti-apoptotic factors that stimulate proliferation of endothelial cells and smooth muscle cells (26-29). In the present study, RT-PCR results indicated that the expression levels of VEGF, vWF, TGF-3 $\beta$ and IL-1 $\beta$ in the infarction zone were significantly increased in the BMSC group compared with the control group. BMSCs have been demonstrated to survive in infarcted myocardium for at least 6 months and the cells expressed muscle markers (21). In our previous study, DiI-labeled BMSCs survived in infarcted myocardium and expressed the cardiac marker, cTnT, vWF and smooth muscle actin at 3 months following transplantation.

In conclusion, in the present study, $\mathrm{Flk} 1^{+} \mathrm{CD} 34^{+} \mathrm{CD} 3$ BMSC transplantation into a mini-swine model of AMI was demonstrated to greatly increase LV function, cardiac blood flow, and vascular density; and decrease cell apoptosis in the long-term postoperative period. The present study provides useful information for the development of potential BMSC-based therapies for myocardial infarction.

\section{Acknowledgements}

This study was supported by a grant from the Youth Foundation of the Second Hospital of Shandong University (grant no. Y2013010068) and the Natural Science Foundation of Shandong Province (grant no. ZR2010HM125).

\section{References}

1. Roger VL, Go AS, Lloyd-Jones DM, et al; American Heart Association Statistics Committee and Stroke Statistics Subcommittee: Heart disease and stroke statistics - 2011 update: a report from the American Heart Association. Circulation 123: e18-e209, 2011.

2. Karapetyan AV, Klyachkin YM, Selim S, et al: Bioactive lipids and cationic antimicrobial peptides as new potential regulators for trafficking of bone marrow-derived stem cells in patients with acute myocardial infarction. Stem Cells Dev 22: 1645-1656, 2013.

3. Williams AR, Hatzistergos KE, Addicott B, et al: Enhanced effect of combining human cardiac stem cells and bone marrow mesenchymal stem cells to reduce infarct size and to restore cardiac function after myocardial infarction. Circulation 127: 213-223, 2013.

4. Welt FG, Gallegos R, Connell J, et al: Effect of cardiac stem cells on left-ventricular remodeling in a canine model of chronic myocardial infarction. Circ Heart Fail 6: 99-106, 2013.

5. Zhang GW, Liu XC, Li-Ling J, et al: Mechanisms of the protective effects of BMSCs promoted by TMDR with heparinized bFGF-incorporated stent in pig model of acute myocardial ischemia. J Cell Mol Med 15: 1075-1086, 2011.

6. Peng C, Yang K, Xiang P, et al: Effect of transplantation with autologous bone marrow stem cells on acute myocardial infarction. Int J Cardiol 162: 158-165, 2013.

7. Hatzistergos KE, Quevedo H, Oskouei BN, et al: Bone marrow mesenchymal stem cells stimulate cardiac stem cell proliferation and differentiation. Circ Res 107: 913-922, 2010.

8. Quevedo HC, Hatzistergos KE, Oskouei BN, et al: Allogeneic mesenchymal stem cells restore cardiac function in chronic ischemic cardiomyopathy via trilineage differentiating capacity. Proc Natl Acad Sci USA 106: 14022-14027, 2009.

9. Gnecchi M, Zhang Z, Ni A and Dzau VJ: Paracrine mechanisms in adult stem cell signaling and therapy. Circ Res 103: 1204-1219, 2008.

10. Luan Y, Liu XC, Zhang GW, et al: Mid-term effect of stem cells combined with transmyocardial degradable stent on swine model of acute myocardial infarction. Coron Artery Dis 21: 233-243, 2010.

11. Wang Y, Liu XC, Zhang GW, et al: A new transmyocardial degradable stent combined with growth factor, heparin, and stem cells in acute myocardial infarction. Cardiovasc Res 84: 461-469, 2009

12. Spadafora M, Varrella P, Acampa W, et al: Direct imaging of viable myocardium by gated SPECT in patients with ischaemic left ventricular dysfunction. Eur J Nucl Med Mol Imaging 37: 1730-1735, 2010.

13. Nagaya N, Kangawa K, Itoh T, et al: Transplantation of mesenchymal stem cells improves cardiac function in a rat model of dilated cardiomyopathy. Circulation 112: 1128-1135, 2005. 
14. Hou M, Yang KM, Zhang H, et al: Transplantation of mesenchymal stem cells from human bone marrow improves damaged heart function in rats. Int J Cardiol 115: 220-228, 2007.

15. Miyahara Y, Nagaya N, Kataoka M, et al: Monolayered mesenchymal stem cells repair scarred myocardium after myocardial infarction. Nat Med 12: 459-465, 2006.

16. Imanishi Y, Saito A, Komoda H, et al: Allogenic mesenchymal stem cell transplantation has a therapeutic effect in acute myocardial infarction in rats. J Mol Cell Cardiol 44: 662-671, 2008.

17. Pittenger MF and Martin BJ: Mesenchymal stem cells and their potential as cardiac therapeutics. Circ Res 95: 9-20, 2004.

18. Choi SC, Kim SJ, Choi JH, et al: Fibroblast growth factor-2 and -4 promote the proliferation of bone marrow mesenchymal stem cells by the activation of the PI3K-Akt and ERK1/2 signaling pathways. Stem Cells Dev 17: 725-736, 2008.

19. Moelker AD, Baks T, van den Bos EJ, et al: Reduction in infarct size, but no functional improvement after bone marrow cell administration in a porcine model of reperfused myocardial infarction. Eur Heart J 27: 3057-3064, 2006.

20. Nanjundappa A, Raza JA, Dieter RS, et al: Cell transplantation for treatment of left-ventricular dysfunction due to ischemic heart failure: from bench to bedside. Expert Rev Cardiovasc Ther 5: 125-131, 2007.

21. Dai W, Hale SL, Martin BJ, et al: Allogeneic mesenchymal stem cell transplantation in postinfarcted rat myocardium: short- and long-term effects. Circulation 112: 214-223, 2005.

22. Yang D, Wang W, Li L, et al: The relative contribution of paracine effect versus direct differentiation on adipose-derived stem cell transplantation mediated cardiac repair. PLoS One 8: e59020, 2013.
23. Kinnaird T, Stabile E, Burnett MS, et al: Local delivery of marrow-derived stromal cells augments collateral perfusion through paracrine mechanisms. Circulation 109: 1543-1549, 2004.

24. Rahbarghazi R, Nassiri SM, Khazraiinia P, et al: Juxtacrine and paracrine interactions of rat marrow-derived mesenchymal stem cells, muscle-derived satellite cells, and neonatal cardiomyocytes with endothelial cells in angiogenesis dynamics. Stem Cells Dev 22: 855-865, 2013.

25. Wang Y, Tang H, Wang D, et al: Pretreatment with transmyocardial revascularization might improve ischemic myocardial function performed with cell transplantation. Circ J 70: 625-630, 2006.

26. Liu MH, Jin H, Floten HS, et al: Vascular endothelial growth factor-mediated, endothelium-dependent relaxation in human internal mammary artery. Ann Thorac Surg 73: 819-824, 2002.

27. Muraoka N, Shum L, Fukumoto S, et al: Transforming growth factor-beta3 promotes mesenchymal cell proliferation and angiogenesis mediated by the enhancement of cyclin D1, Flk-1, and CD31 gene expression during CL/Fr mouse lip fusion. Birth Defects Res A Clin Mol Teratol 73: 956-965, 2005.

28. Li H, Zuo S, He Z, et al: Paracrine factors released by GATA-4 overexpressed mesenchymal stem cells increase angiogenesis and cell survival. Am J Physiol Heart Circ Physiol 299: H1772-H1781, 2010.

29. Takehara N, Tsutsumi Y, Tateishi K, et al: Controlled delivery of basic fibroblast growth factor promotes human cardiosphere-derived cell engraftment to enhance cardiac repair for chronic myocardial infarction. J Am Coll Cardiol 52: 1858-1865, 2008. 